(2.9\%) straight. 918/1186 (77.4\%) were HIV-negative, 42/1186 (3.5\%) HIV-positive, 188/1186 (15.9\%) never tested, and 38/ 1186 (3.2\%) unknown status. The median age of first sexual behaviour with another man was 17.6 years (6-41). The median age of disclosure of sexuality to: family is 18 years $(8-45)$ and friends 17 years (11-41); sexual health services 892/1186 $(66.6 \%)=19.0$ years $(14-54)$; and to primary care $522 / 1186$ $(44 \%)=21.2$ years $(13-54)$. There is a difference between age of first sexual experience and disclosure to primary care of 3.6 years.

Discussion/conclusion Delayed disclosure to healthcare professionals of sexuality by MSM is likely to impede the uptake of important health interventions in MSM.

\section{P065 LACK OF EXPOSURE TO GENITOURINARY MEDICINE (GUM) IS LEADING TO A RECRUITMENT CRISIS}

${ }^{1,3}$ Anna Hartley ${ }^{*},{ }^{2-4}$ Daniel Richardson. ${ }^{1}$ Barts Health NHS Trust, London, UK; ${ }^{2}$ Brighton \& Sussex University NHS Trust, Brighton, UK; ${ }^{3}$ British Association for Sexual Health and HIV; ${ }^{4}$ Brighton \& Sussex Medical School, Sussex, UK

\subsection{6/sextrans-2016-052718.119}

Background In 2015, genitourinary medicine (GUM) filled 46\% of its national training numbers. Reasons for low recruitment are unclear. In February, GUM exhibited at the Royal College of Physicians (RCP) Medical Careers Day attended by undergraduates (UGs) and junior doctors (JDs).

Aim We aimed to assess the factors that attract and deter delegates from choosing a career in GUM.

Methods A survey was conducted amongst delegates who visited the GUM stall at the Careers Day.

Results 93\% (25/27) of delegates who visited the stall completed the survey (14 UGs, 8 foundation year (FY) doctors, 3 other). $33 \%(8 / 24)$ would like a career in GUM (54\% (13/24) not sure; $13 \%(3 / 24)$ were not interested in GUM). 92\% (23/25) would like/have liked a rotation in GUM as a JD. 76\% (19/25) were exposed to GUM in medical school (86\% FYs, 50\% UGS). One delegate had done a rotation in GUM as a FY. The table shows the main factors that attract delegates to or deter them from a career in GUM:

\begin{tabular}{llll}
\multicolumn{2}{l}{ Abstract P065 Table 1 } \\
\hline Attracts & $\begin{array}{l}\text { Number of } \\
\text { delegates }\end{array}$ & Deters & $\begin{array}{l}\text { Number of } \\
\text { delegates }\end{array}$ \\
\hline $\begin{array}{l}\text { "Variety/interesting } \\
\text { speciality" }\end{array}$ & 11 & $\begin{array}{l}\text { Lack of exposure to } \\
\text { GUM }\end{array}$ & 5 \\
Work-life balance & 7 & $\begin{array}{l}\text { Lack of inpatient } \\
\text { work }\end{array}$ & 3 \\
Research opportunities & 4 & & \\
HIV & 4 & & \\
\hline
\end{tabular}

Conclusion This survey shows that there is interest in GUM at UG/JD level. A variety of factors appealed to delegates, with fewer deterrents, of which "lack of exposure" predominated. Delegates would like GUM rotations as JDs. Optimising exposure to GUM within medical schools and JD rotations should be a priority in order to attract trainees to GUM.
P066 TRANSMISSION OF NEISSERIA GONORRHOEAE AMONG MEN WHO HAVE SEX WITH MEN: AN ANATOMICAL SITE-SPECIFIC MATHEMATICAL MODEL AND IMPACT OF MOUTHWASH

1,2 Lei Zhang ${ }^{*}$, ${ }^{3}$ David Regan, ${ }^{1,2}$ Eric Chow, ${ }^{1,2}$ Vincent Cornelisse, ${ }^{5}$ Manoj Gambhir, 1,2Jane Hocking, ${ }^{1}$ Christopher Fairley. ${ }^{1}$ Melbourne Sexual Health Centre, Melbourne, Australia; ${ }^{2}$ Central Clinical School, Faculty of Medicine, Monash University, Melbourne, Australia; ${ }^{3}$ Kirby Institute, Faculty of Medicine, University of New South Wales, Sydney, Australia; ${ }^{4}$ Melbourne School of Population and Global Health, University of Melbourne, Melbourne, Australia; ${ }^{5}$ School of Public Health and Preventive Medicine, Faculty of Medicine, Monash University, Melbourne, Australia

\subsection{6/sextrans-2016-052718.120}

Background/introduction Epidemiological data suggest that kissing may play a significant role in gonorrhoea transmission.

Aim(s)/objectives We developed a transmission model to explain anatomical site-specific prevalence of gonorrhoea among Australian men who have sex with men (MSM) and evaluate the population-level impacts of screening and the use of mouthwash as interventions in reducing its transmission.

Methods We constructed a gonorrhoea transmission model to estimate the per-act transmission probability. Using Monte-Carlo simulations, we constructed hypothetical scenarios to evaluate its population-level impacts.

Results We have previously reported the prevalence of pharyngeal, anal and urethral gonorrhoea as being 10.6\% (95\%CI 8.1$12.2 \%), 8.6 \%(6.7-10.4 \%)$ and $0.17 \%(0.02-0.24 \%)$, respectively, in Australian MSM. Calibrated to these data, the modelestimated per-act transmission probability for gonorrhoea was high for transmission from urethra-to-anus (46.0\% [41.752.6\%]) and from-urethra to-pharynx (49.6\% [46.7-53.8\%]). Although pharynx-to-pharynx transmission through kissing has only a transmission probability of $17.4 \%$ (16.0-21.0\%), it accounts for nearly three quarters of the annual incident cases (74.6\% [70.0-82.4\%]). A substantial increase in gonorrhoea screening from the current $40 \%$ to $100 \%$ may only halve gonorrhoea prevalence in MSM. In contrast, the use of mouthwash with moderate efficacy (extra 1\% bacterial load reduction/use) would further reduce the corresponding site prevalence to $2.4 \%$ $(1.8 \%-3.7 \%), 2.2 \% \quad(1.6-3.2 \%)$ and $0.02 \% \quad(0.01-0.03 \%)$, whereas a high efficacy (extra $1.5 \%$ reduction/use) may achieve a scenario of close to elimination.

Discussion/conclusion Our results suggests that kissing may be the key driver of community prevalence. If antibacterial mouthwash is effective and widely used, it may contribute to controlling the gonorrhoea epidemic.

\section{P067 WHY DON'T PEOPLE WITH GENITO-URINARY SYMPTOMS GO TO SEXUAL HEALTH CLINICS? A MIXED METHODS STUDY ABOUT MEANINGS OF SYMPTOMS AND CARE-SEEKING USING THE THIRD NATIONAL SURVEY OF SEXUAL ATTITUDES AND LIFESTYLES (NATSAL-3)}

${ }^{1}$ Fiona Mapp*, ${ }^{1}$ Ford Hickson, ${ }^{2}$ Cath Mercer, ${ }^{1}$ Kaye Wellings. 'London School of Hygiene \& Tropical Medicine, London, UK; ${ }^{2}$ University College London, London, UK

\subsection{6/sextrans-2016-052718.121}

Background/introduction There are both individual and public health benefits in people responding to genito-urinary symptoms effectively. Sexual health clinics are best equipped for managing symptoms but not everyone with symptoms chooses to attend. 